\title{
Sustentabilidade do Saldo em Transações Correntes e seus Impactos sobre o Crescimento Econômico
}

Marcelo Curado ${ }^{*}$

\section{Introdução}

Durante os anos noventa, mais particularmente após a implantação do Plano Real em 1994, a discussão sobre os desequilíbrios externos da economia brasileira foi um tema de intenso debate entre economistas de diversas orientações teóricas. Em grande medida, isto ocorreu como resultado do agravamento destes desequilíbrios a partir da implantação do plano, com destaque para o debate sobre os déficits comerciais e em transações correntes.

Entre 1994 e 1998 o debate foi concentrado na discussão sobre a sustentabilidade dos déficits em transações correntes através da atração de capitais externos de curto e longo prazo. Economistas críticos à política econômica adotada pelo governo argumentavam que a combinação de desequilíbrios externos e a adoção de um regime de administração do câmbio - com efetiva valorização da taxa de câmbio real - seriam insustentáveis ao longo do tempo. A ocorrência de ataques especulativos no México em 1994, no Sudeste da Ásia em 1997 e na Rússia em 1998 seriam exemplos reais da insustentabilidade do financiamento sistemático de seus desequilíbrios externos através da estratégia de atração de capitais, sobretudo de curto prazo.

Do ponto de vista dos economistas do governo, o desequilíbrio externo era um tema de menor importância, quando não inexistente. $O$ argumento apresentava-se em duas vertentes. A primeira, mais simplória, afirmava que o Brasil era uma economia em desenvolvimento e como tal deveria ser uma absorvedora de poupança externa ${ }^{27}$. Somava-se a este argumento a situação de extrema liquidez internacional que permitia - através da entrada de capitais de curto e longo prazo - financiar o desequilíbrio externo e ao mesmo tempo acumular reservas internacionais. Outra vertente, que teve em Gustavo Franco então presidente do Banco Central do Brasil seu principal defensor, argumentava que não existia valorização da moeda local. A taxa de câmbio vigente seria fruto de mudanças estruturais na economia brasileira, em particular dos elevados ganhos de produtividade verificados no

\footnotetext{
* Professor Adjunto do Departamento de Economia da Universidade Federal do Paraná. Endereço eletrônico: mcurado@ufpr.br

${ }^{27}$ Vale lembrar que por definição a poupança externa da economia é igual ao déficit em transações correntes do Balanço de Pagamentos.
} 
período. Nesta concepção o ajuste do saldo comercial e em transações correntes seria apenas uma questão de tempo.

O ataque especulativo contra o Real em 1999 demonstrou, na prática, quem de fato tinha razão. No entanto, o abandono da administração da taxa de câmbio e a efetiva adoção do sistema de câmbio flutuante com intervenção (dirty floating) em janeiro de 1999 tinham ao menos um ponto positivo. Esperava-se, o que de fato aconteceu com um lapso temporal, que a desvalorização do Real resolvesse o desequilíbrio externo em transações correntes. De fato, como demonstram as evidências empíricas, a partir de 2003 este saldo passa a apresentar resultados positivos de forma recorrente. Mais recentemente, este resultado continuou a ser observado num contexto de valorização da moeda, o que tem contribuído para a formação de uma visão equivocada sobre a atual situação das contas externas brasileiras.

Este artigo pretende discutir a natureza da atual situação das contas externas brasileiras, em particular dos resultados em transações correntes. A partir deste ponto o artigo busca analisar em que medida as contribuições teóricas da literatura pós-keynesiana de crescimento com restrição do Balanço de Pagamentos - extensivamente discutida no final dos anos noventa - apresentam-se ainda relevantes.

O artigo está organizado da seguinte forma. Após esta breve introdução, apresenta-se uma caracterização da atual situação do saldo em transações correntes. A seção 2 apresenta uma revisão do referencial teórico pós-keynesiano para uma economia aberta elaborado a partir da contribuição original de Thirlwall (1979). A seção 4 apresenta as considerações finais do trabalho.

\section{Uma Análise do Saldo em Transações Correntes}

O primeiro elemento que deve ser destacado é que a ocorrência de superávits em transações correntes é, em si, um elemento positivo e que, de uma forma geral, contraria a tendência de déficits sistemáticos nesta conta. O gráfico 1 apresenta a evolução anual do saldo em transações correntes para o período que se estende de 1967 a 2005, evidenciando o caráter praticamente estrutural do desequilíbrio externo em transações correntes da economia brasileira. 
Gráfico 1. Saldo em Transações Correntes (US\$ milhões) - 1967-2005

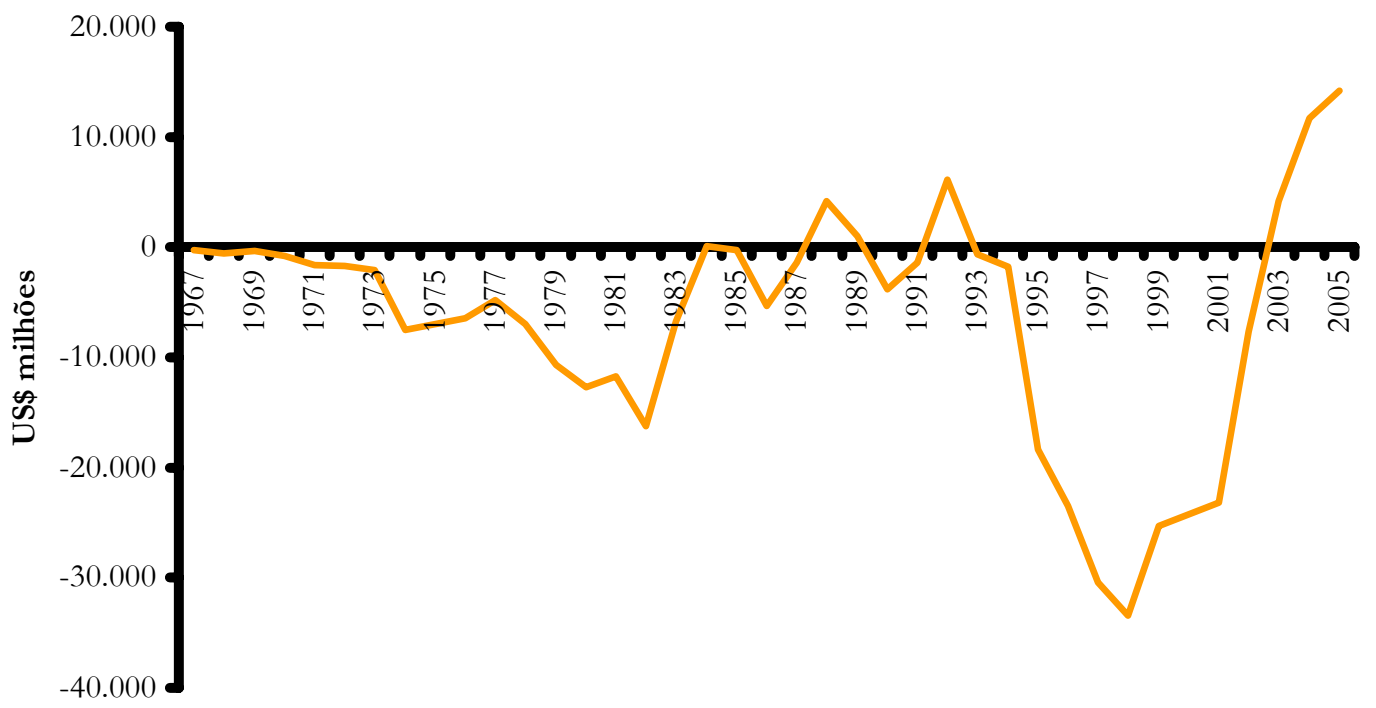

Ano

Fonte: Ipeadata.

A ocorrência de superávit em transações correntes é um fato (raro) que deve ser comemorado por diversas razões. Dentre elas, vale destacar um aspecto macroeconômico. A verificação de um saldo positivo nesta conta desvincula o "fechamento" do Balanço de Pagamentos da necessidade de gerar um superávit na Conta Capital e Financeira através da atração de capitais de curto prazo. No entanto, tão importante quanto verificar esta melhora é qualificá-la. A primeira qualificação é apontar qual a fonte para esta situação. As evidências selecionadas pelo gráfico 2 ajudam a elucidar o tema. 
Gráfico 2. Balanço de Pagamentos - Contas Selecionadas:

Balança Comercial e Serviços e Rendas - US\$ milhões - anual

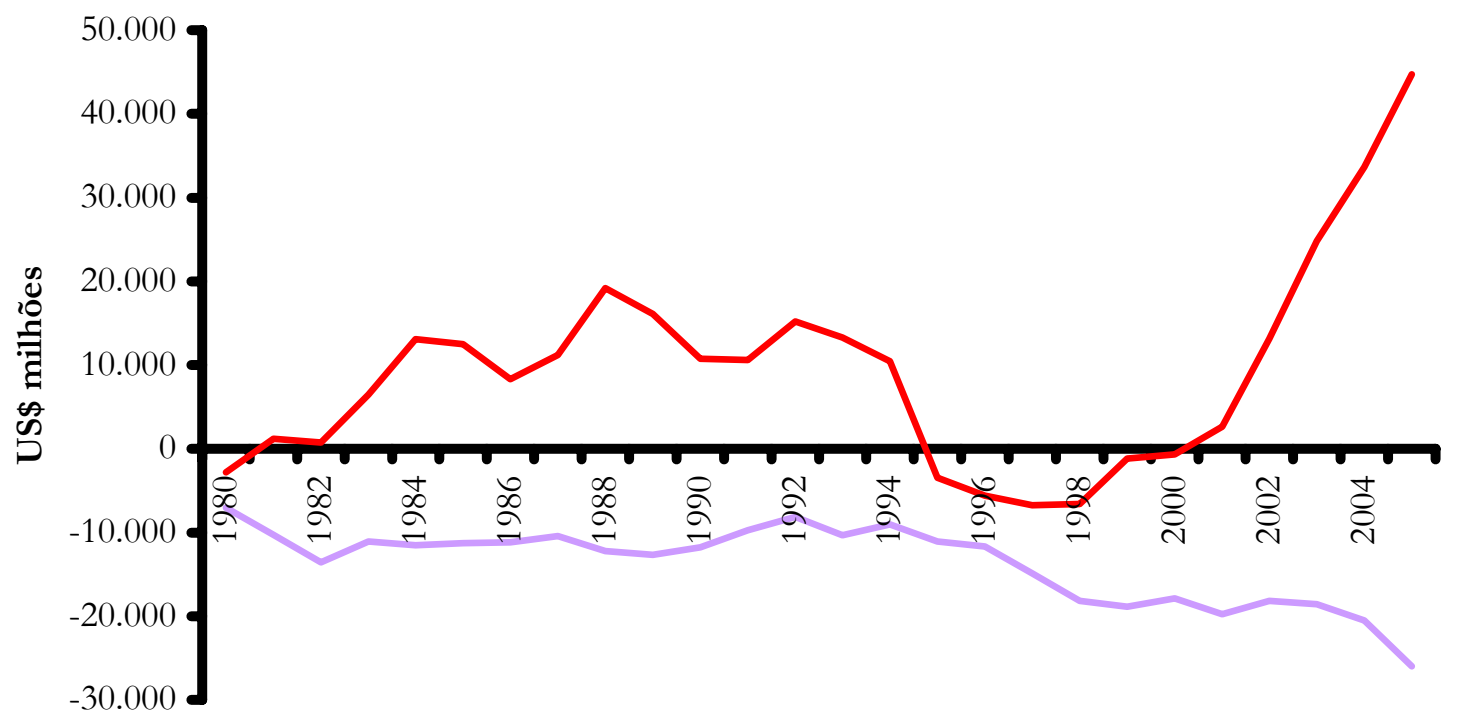

Balança comercial Serviços e rendas

Fonte: Ipeadata

O gráfico 2 apresenta o comportamento mensal da Balança Comercial brasileira e da conta de Serviços e Rendas para o período que se estende de janeiro de 1980 a agosto de 2006. É importante notar dois elementos:

1. a melhora no resultado em transações correntes é fruto dos superávits comerciais observados sistematicamente desde 2001 ; e

2. A conta de Serviços e Rendas é estrutural e crescentemente deficitária.

Este segundo ponto tem sido relativamente negligenciado por boa parte das análises realizadas recentemente sobre a evolução do Balanço de Pagamentos brasileiro. É importante notar que permanece inalterado o caráter eminentemente exportador de capital da conta de Serviços e Rendas do Balanço de Pagamentos, o que se deve, em particular, em função do comportamento das contas de juros e de lucros e dividendos.

A manutenção dos bons resultados observados recentemente pelo saldo em Transações Correntes tem, portanto, como premissa a sustentação dos elevados superávits comerciais. Vejamos, mais detalhadamente alguns aspectos sobre o comportamento das transações comerciais.

A tabela 1 apresenta os dados de importações (FOB) e exportações (FOB) para o período que se estende de 1994 a 2005 . Como pode ser observado, os resultados positivos 
do saldo comercial decorrem essencialmente de uma melhora no comportamento das exportações, merecendo destaque seu crescimento desde 2003. Chama também atenção o crescimento recente das importações (2004 e 2005, em especial) o que, em alguma medida, pode estar refletindo o comportamento recente de valorização do Real.

\section{Tabela 1. Exportações (FOB) e Importações FOB)}

US\$ milhões e variação percentual - 1994 a 2005

\begin{tabular}{ccccc}
\hline Período & $\begin{array}{c}\text { Importações - (FOB) } \\
\text { - US\$(milhões) }\end{array}$ & $\begin{array}{c}\text { Variação } \\
\mathbf{( \% )}\end{array}$ & $\begin{array}{c}\text { Exportações - (FOB) } \\
\text { - US\$(milhões) }\end{array}$ & Variação \% \\
\hline 1994 & 33.079 & - & 43.545 & - \\
1995 & 49.970 & $51,06 \%$ & 46.506 & $6,80 \%$ \\
1996 & 53.346 & $6,76 \%$ & 47.747 & $2,67 \%$ \\
1997 & 59.842 & $12,18 \%$ & 52.986 & $10,97 \%$ \\
1998 & 57.714 & $-3,56 \%$ & 51.120 & $-3,52 \%$ \\
1999 & 49.210 & $-14,73 \%$ & 48.011 & $-6,08 \%$ \\
2000 & 55.783 & $13,36 \%$ & 55.086 & $14,74 \%$ \\
2001 & 55.582 & $-0,36 \%$ & 58.223 & $5,69 \%$ \\
2002 & 47.232 & $-15,02 \%$ & 60.362 & $3,67 \%$ \\
2003 & 48.260 & $2,18 \%$ & 73.084 & $21,08 \%$ \\
2004 & 62.782 & $30,09 \%$ & 96.475 & $32,01 \%$ \\
2005 & 73.551 & $17,15 \%$ & 118.308 & $22,63 \%$ \\
\hline
\end{tabular}

Fonte: Ipeadata

A melhora do saldo comercial, em particular do valor exportado não pode, no entanto, ser atribuída, do ponto de vista global, a uma melhora nos termos de troca como sugere o gráfico 3 .

Gráfico 3. Termos de Troca* 1974-2005

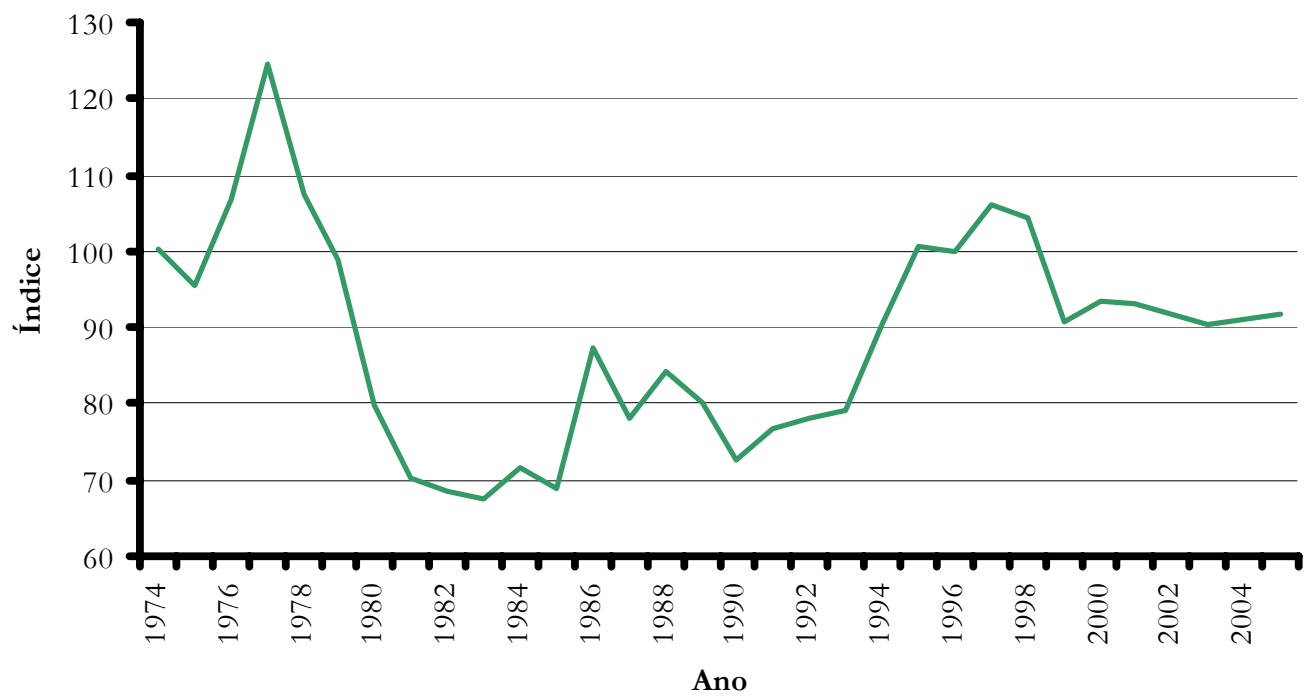

*Relação entre o índice de preços das exportações e das importações.

Ano Base $(1996=100)$ 
O gráfico 3 apresenta os termos de troca (relação entre o índice de preços das exportações e das importações) para o período compreendido entre 1974 e 2005, tomando 1996 como ano base. O gráfico sugere que não há uma melhora no comportamento recente dos termos de troca. Pelo contrário, o que se observa é uma piora dos termos de troca, sobretudo, após 2000. Em suma, a melhora no saldo comercial e, em particular, no valor das exportações não pode ser explicada por uma elevação nos preços dos produtos exportados ou por uma queda nos preços dos produtos importados. Na realidade, como demonstra o gráfico 4 a melhora no valor das exportações deve ser atribuída a uma forte expansão no quantum exportado.

\section{Gráfico 4. Quantum Exportado - produtos básicos, manufaturados e semi-manufaturados}

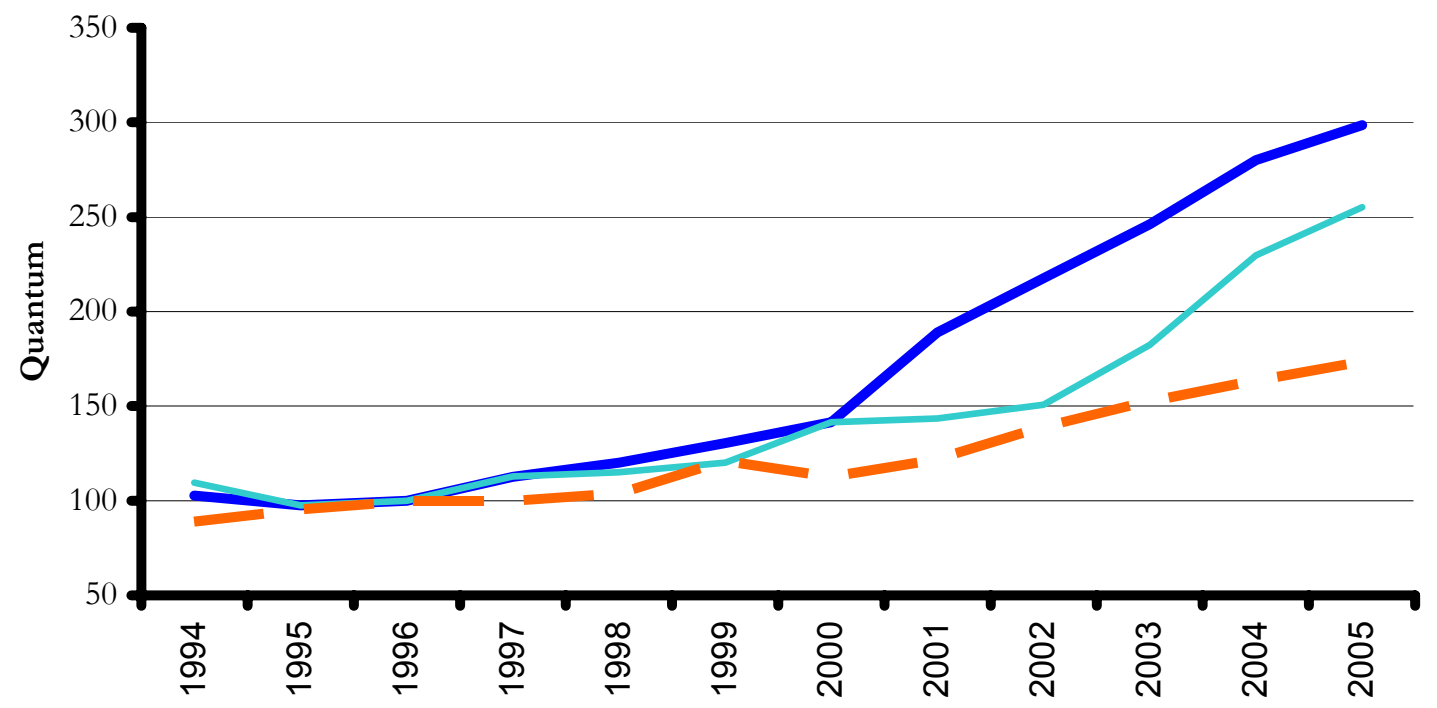

- Produtos básicos Produtos manufaturados $\longrightarrow$ Produtos semi-manufaturados

Fonte: Ipeadata

A observação do gráfico 4 revela ainda uma outra característica importante: o crescimento do quantum exportado ocorreu de forma mais pronunciada nos setores exportadores de produtos básicos, seguido pelos setores exportadores de manufaturados e de semi-manufaturados.

A análise do comportamento da pauta de exportações brasileira para o período compreendido entre 1994 e 2006 revela outros elementos que devem ser considerados na 
análise da evolução recente das exportações. O gráfico 5 - elaborado a partir de dados organizados pelo Boletim de Economia \& Tecnologia da UFPR - permite esta análise.

Gráfico 5. Pauta de Exportações Brasileira - 1994 a 2005

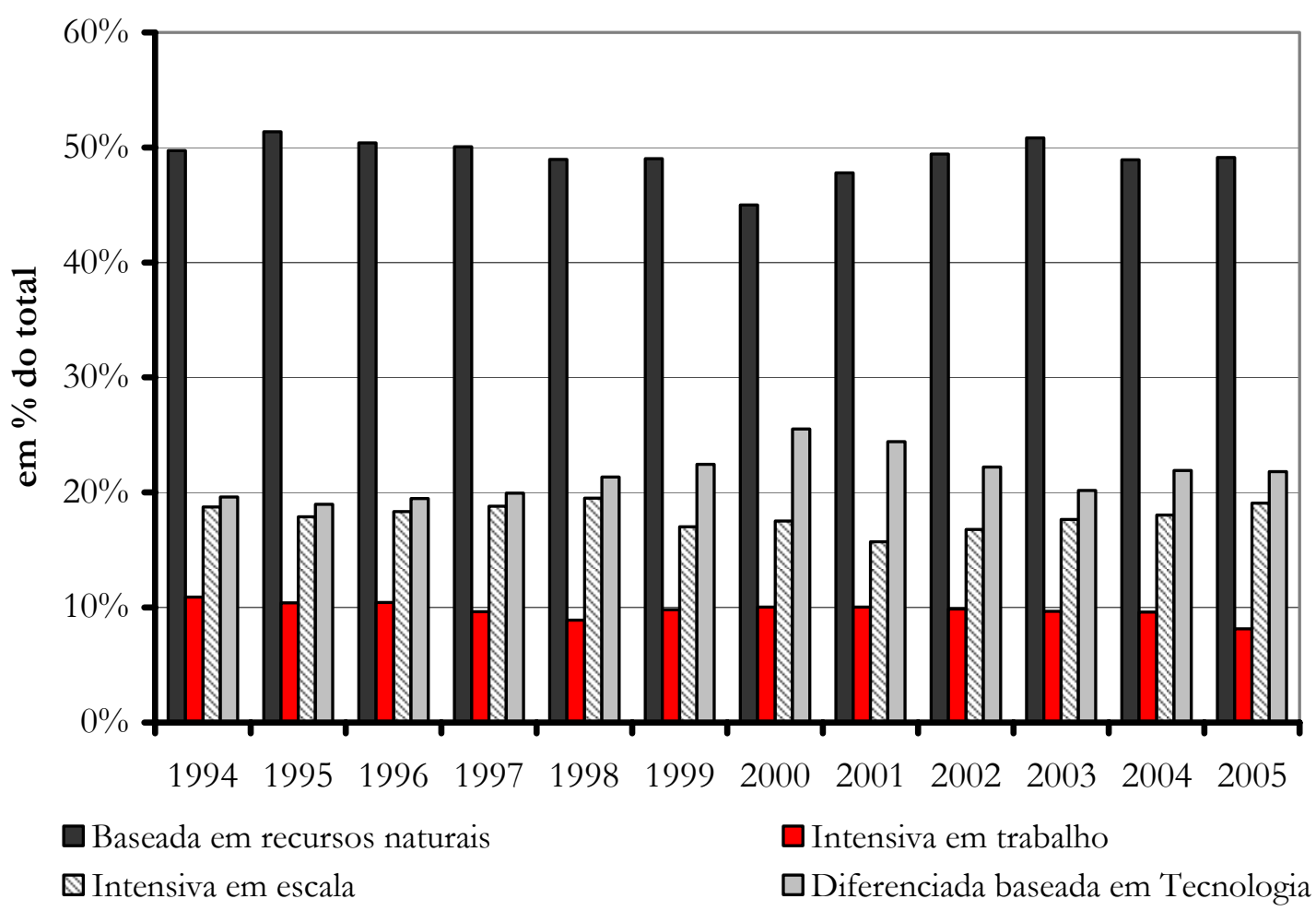

Fonte: Economia \& Tecnologia da UFPR

A pauta de exportações brasileira foi classificada em quatro grupos: 1. Baseada em Recursos Naturais; 2. Intensiva em Tecnologia; 3. Intensiva em Escala e 4. Diferenciada e Baseada em Tecnologia ${ }^{28}$.

O aspecto que chama atenção para a análise é a profunda estabilidade da pauta de exportações brasileiras para este período. As exportações Baseadas em Recursos Naturais mantêm praticamente inalterada a sua participação - em torno de $50 \%$ do total exportado -

28 Baseada em recursos naturais: petróleo e carvão; refino de petróleo ;outros produtos alimentares; metalurgia não ferrosos; minerais não metálicos; celulose, papel e gráfica; extrativa mineral; açúcar; café; laticínios; óleos vegetais; beneficiamento de produtos vegetais; abate de animais; agropecuária. Intensiva em trabalho: Têxtil; calçados; madeira e mobiliário; artigos de vestuário. Intensiva em escala: elementos químicos; plástica; veículos automotores; borracha; químicos diversos; siderurgia outros produtos metalúrgicos. Diferenciada e Baseadas em ciência: máquinas e tratores material; indústrias diversas equipamentos eletrônicos; peças e outros veículos; farmacêutica e perfumaria. 
ao longo do tempo. Da mesma forma, os setores que compõem as exportações intensivas em trabalho mantêm em torno de $10 \%$ sua participação no total exportado. Por outro lado, os setores responsáveis pelas exportações classificadas como Diferenciadas e Baseada em Tecnologia mantêm em torno de $20 \%$ a sua participação no valor total das exportações.

O contexto de estabilidade econômica, a abertura comercial processada ao longo dos anos 90 e as mudanças de regime cambial foram, portanto, incapazes de alterar a configuração da pauta de exportações, de acordo com os dados organizados pelo Boletim de Economia \& Tecnologia da UFPR.

Não há, portanto, ao menos no que se refere à composição da pauta de exportações um processo de diversificação estrutural da pauta exportadora. Em outras palavras, não há uma melhora qualitativa da pauta exportadora brasileira ao longo do período analisado, tendo em vista a manutenção da elevada participação dos setores Baseados em Recursos Naturais e Intensivos em Trabalho no valor total das exportações brasileiras.

Estas evidências são preocupantes do ponto de vista da sustentabilidade dos superávits em transações correntes, pois tornam evidente a forte vinculação deste resultado com a situação excepcionalmente favorável da conjuntura internacional. A concentração da pauta de exportação em setores pouco dinâmicos - em particular setores de baixa elasticidade-renda - e de baixo conteúdo tecnológico é também preocupante do ponto de vista das possibilidades de crescimento do produto com equilíbrio do Balanço de Pagamentos. Este ponto pode ser analisado a partir da contribuição teórica pós-keynesiana para uma economia aberta apresentada originalmente por Thirlwall (1979).

\section{Crescimento com Equilíbrio do Balanço de Pagamentos - uma breve revisão da contribuição pós-keynesiana}

Nesta seção será apresentado o modelo básico de crescimento com equilíbrio do Balanço de Pagamentos. O ponto de partida desta literatura foi o trabalho original de Thirlwall (1979). O trabalho demonstra que o Balanço de Pagamentos é um componente crucial na restrição do crescimento de longo prazo para diversas economias, em particular para economias menos desenvolvidas.

Thirlwall \& Hussain (1982) elaboram uma versão mais desenvolvida deste modelo original. Esta versão incorpora a possibilidade de financiar os desequilíbrios nas transações correntes através da entrada de capital, ou seja, incorpora a possibilidade de existência de um desequilíbrio inicial do saldo em transações correntes financiado por uma entrada de capital. 
A apresentação do modelo básico irá seguir a versão mais completa elaborada por Thirlwall \& Hussain (1982). Parte-se, portanto, de uma situação inicial na qual o equilíbrio do BP pode ser representado por:

$$
P d X+F=P f M E
$$

Onde: $X$ é o volume de exportações; $P d$ é o preço doméstico das exportações; $M$ é o volume de importações; Pf é o preço das importações; E é a taxa de câmbio (medida como o preço doméstico da moeda estrangeira) e $F$ é o valor nominal dos fluxos de capital medido em moeda corrente.

Em termos de taxa de variação as variáveis da equação (1) podem ser expressas por:

$$
\theta\left(p_{d}+x\right)+(1-\theta) f=p_{f}+m+e
$$

Tanto (1) quanto (2) representam condições de equilíbrio no Balanço de Pagamentos. A única diferença entre elas é que a primeira se refere ao equilíbrio em sua forma estática, enquanto a segunda se refere ao equilíbrio do Balanço de Pagamentos em sua forma "dinâmica".

Thirlwall \& Hussain (1982), seguindo a contribuição original de Thirlwall (1979), assumem funções padrão para a demanda por exportações e importações descritas por:

$$
\begin{aligned}
& M=a\left(\frac{P_{f} E}{P_{d}}\right)^{\psi} Y^{\pi}(3) \\
& X=b\left(\frac{P_{d}}{P_{f} E}\right)^{\eta} Z^{\varepsilon}(4)
\end{aligned}
$$

Onde: $a$ e b constantes; $\psi$ a elasticidade-preço da demanda por importações $(\psi<0) ; \eta$ a elasticidade-preço da demanda por exportações $(\eta<0)$; Y a renda doméstica; Z o nível da renda do "mundo"; $\pi$ a elasticidade-renda da demanda por importações $(\pi>0)$ e $\varepsilon$ a elasticidade-renda da demanda por exportações $(\varepsilon>0)$.

A interpretação das equações (3) e (4) é direta. A primeira afirma que as importações são determinadas pelo comportamento da renda doméstica (ponderada pela sua respectiva elasticidade-renda) e pelo comportamento dos preços relativos (ponderado pela respectiva elasticidade-preço). Da mesma forma, as exportações dependem do comportamento da renda 
do resto do mundo (ponderada pela elasticidade renda) e pelos preços relativos (ponderado pela elasticidade preço). Em termos de taxa de variação das variáveis, obtemos:

$$
\begin{aligned}
& m=\psi\left(p_{f}+e+p_{d}\right)+\pi y(5) \\
& x=\eta\left(p_{d}-e-p_{f}\right)+\varepsilon z(6)
\end{aligned}
$$

Substituindo (5) e (6) em (2) obtemos a taxa de crescimento consistente com o equilíbrio do Balanço de Pagamentos, descrita por (7):

$$
y_{b}=(\theta \eta+\phi)\left(p_{d}-e-p_{f}\right)+\left(p_{d}-e-p_{f}\right)+\theta \varepsilon z+(1-\theta)\left(f-p_{d}\right)
$$

A equação (7) sugere que a taxa de crescimento com equilíbrio no Balanço de Pagamentos depende essencialmente: 1. dos parâmetros de elasticidade-preço e renda; 2. dos preços relativos; 3. da taxa de crescimento do resto do mundo e 4. do fluxo de capitais.

Com o intuito de simplificar a análise, assumem-se duas hipóteses: 1) $p d=p f+e$, ou seja, os preços relativos mensurados numa moeda comum permanecem inalterados; e 2) parte-se de uma condição inicial de equilíbrio no saldo em transações correntes no qual o fluxo de capital é nulo.

A partir destas simplificações pode-se chegar a uma versão mais simplificada da equação que descreve a taxa de crescimento compatível com o equilíbrio do Balanço de Pagamentos descrita por (8)

$$
Y b=\varepsilon z / \pi=X / \pi
$$

A Lei de Thirlwall expressa pela equação (8) sugere que a taxa de crescimento com equilíbrio do Balanço de Pagamentos depende de um fator exógeno - a taxa de crescimento resto do mundo $(z)$ - e dos parâmetros, assumidos constantes no modelo original, de elasticidade-renda da demanda por exportações e importações. Essencialmente, quanto maior a taxa de crescimento do resto do mundo ( $\mathrm{z}$ ) e a elasticidade-renda da demanda por exportações $(\varepsilon)$ e menor a elasticidade-renda da demanda por importações $(\pi)$ maior a taxa de crescimento compatível com o equilíbrio do Balanço de Pagamentos.

Admitindo-se como hipótese a existência de uma elevada correlação entre o padrão de especialização da economia e os valores dos parâmetros de elasticidade-renda ${ }^{29}$, a situação

\footnotetext{
29 Supondo, por exemplo, que produtos intensivos em trabalho e em recursos naturais tenham uma baixa elasticidade-renda da demanda, enquanto produtos intensivos em conhecimento tenham uma elasticidade-renda relativamente maior.
}

80 
verificada na seção anterior para a economia brasileira torna-se preocupante do ponto de vista de suas possibilidades de crescimento com equilíbrio do Balanço de Pagamentos.

A rigor, seguindo a Lei de Thirlwall, pode-se argumentar que a atual situação da economia brasileira - na qual é patente a inexistência de uma restrição externa ao crescimento - é derivada da expansão do resto do mundo (z), ou seja, é um fenômeno de natureza conjuntural que pode (e provavelmente será) alterado em algum momento.

Em suma, um corolário da Lei de Thirlwall é que o padrão de especialização de uma economia é um elemento essencial na definição da taxa de crescimento que é compativel com o equilíbrio no Balanço de Pagamentos. A manutenção de um padrão de especialização concentrado em setores pouco dinâmicos impõe, em períodos de contração da economia mundial, limites claros a capacidade de expansão do produto com equilíbrio do Balanço de Pagamentos.

\section{Considerações Finais.}

Este artigo procurou demonstrar que a atual situação do saldo em transações correntes da economia brasileira é fruto da excepcional situação da economia mundial. Argumenta-se também que a manutenção de uma elevada concentração da pauta de exportações em setores básicos e intensivos em trabalho é preocupante. O baixo dinamismo, sobretudo no que se refere à reduzida elasticidade-renda da demanda destes produtos, pode contribuir - num contexto de redução da expansão dos fluxos comerciais em nível internacional - para uma deterioração da situação comercial do país, o que em última analise deve contribuir para uma limitação nas possibilidades de expansão do produto.

\section{Referências Bibliográficas}

McCombie, J.S.L \& Thirlwall, A.P. Economic Growth and Balance of Payments Constraint. St Martin's Press, New York, 1994.

Thirlwall, A.P \& Hussain, M,N. The Balance of Payments Constraint, Capital Flows and Growth Rates Differences Between Developing Countries. Oxford Economic Papers, n.10, p. 498-509, 1979 
